Çukurova Üniversitesi Mühendislik Mimarlık Fakültesi Dergisi, 35(3), ss. 679-686, Eylül 2020

\title{
Horzum (Feke/Adana) Çinko-Kurşun Cevherleşmesinin 3 Boyutlu Modellemesi
}

\author{
Ceren Gizem ÇETIN ${ }^{1}$, Mustafa AKYILDIZ ${ }^{* 1}$ \\ Çukurova Üniversitesi, Mühendislik Mimarllk Fakültesi, Jeoloji Mühendisliği Bölümü, Adana
}

Geliş tarihi: 25.08 .2020

Kabul tarihi: 23.10 .2020

\section{$\ddot{O} z$}

Horzum kurşun Çinko yatakları Kozan-Feke ilçeleri arasında yer almaktadır. Cevherleşme K-G yönlü yaklaşık $20 \mathrm{~km}$ boyunca devam etmektedir. Kurşun çinko cevherleşmesi kristalize kireçtaşları, dolomit ve dolomititik kireçtaşlarından oluşan orta Kambriyen yaşlı Çaltepe formasyonuna ait açık renkli kireçtaşları içinde bulunmakta, cevheleşmenin genel duruşu KD-GB doğrultulu ve GD'ye eğimli olarak gözlenmektedir. Cevherleşme kristalize kireçtaşları, dolomit ve dolomititik kireçtaşlarından oluşan orta Kambriyen yaşı Çaltepe formasyonuna ait açık renkli kireçtaşları içinde bulunmaktadır. Cevherleşmede birincil sülfürlü mineraller; galenit, sfalerit, pirit ve az miktarda kalkopirittir. Oksitlenmiş cevher zonunda ise hidrozinkit, simitsonit, götit, limonit ve az oranda serüzit mineralleri gelişmiştir. Blok model yöntemiyle yapılan hesaplamalarda Horzum Kurşun-Çinko yatağında \%5 üzeri tenörde 108000 ton cevher rezervi tespiti edilmiştir.

Anahtar Kelimeler: Horzum, Kurşun, Çinko, Rezerv, Cevherleşme

\section{D Ore Modeling of Horzum (Feke/Adana) Zinc-Lead Mineralization}

\begin{abstract}
Horzum lead Zinc deposits are located between Kozan-Feke districts. Mineralization continues for about $20 \mathrm{~km}$ in N-S direction. Lead zinc mineralization is within the light colored limestones belonging to middle Cambrian aged Çaltepe formation consisting of crystallized limestones, dolomite and dolomitic limestones, and the general elongation of the mineralization is observed in NE-SW direction and inclination to SE. Mineralization is located within the light colored limestones of the medium Cambrian aged Çaltepe formation consisting of crystallized limestones, dolomite and dolomititic limestones. Primary sulphide minerals in mineralization; galenite, sphalerite, pyrite and few photographs are chalcopyrite. In the oxidized ore zone, hydrozinkite, simitsonite, goethite, limonite and fewer serusite minerals have developed. In the calculations made with the block model method, 108000 tons of reserve was determined in 5\% higher grade in Horzum Lead - Zinc bed.
\end{abstract}

Key Words: Horzum, Lead, Zinc, Reserve, Mineralization

\footnotetext{
*Sorumlu yazar (Corresponding author): Mustafa AKYILDIZ, akyildzm@cu.edu.tr
} 


\section{GíRiş̧}

Madencilik ilk yatırım maliyetlerinden dolayı riski fazla olan bir sektördür. Bu nedenle üretim öncesi yapılan planlamanın amacı, yatırım maliyetlerini ve risk katsayısını düşürmektir. Planlamanın aşamalarından biri de cevher yataklarının 3 boyutlu modellemesidir. Çünkü güvenilir kaynak ve rezerv tahmini ilk yatırım için çok önemlidir.

İlk yatırım riskini en aza indirmek için maden kaynak tahminin gerçeğe en yakın şekilde doğru olarak yapılması gerekmektedir. Yanlış, gerçekten uzak kaynak tahminleri; yanlış yatırım kararları, proje maliyetinin planlananın üzerine çıkması, projenin geç tamamlanması, fazladan çıkan maliyetler, düşük maden üretimi gibi kötü senaryolar ortaya çıkarabilmektedir.

Maden kaynak tahminini gerçeğe en yakın ve doğru şekilde yapabilmek için: yatak hakkında jeolojik bilgiye sahip olmak, jeolojik kontrolün tenör üzerindeki etkisinin tam anlaşılmış olması, örnekleme yapılırken gerekli hassasiyet ve analiz kalitesi, doğru ve eksiksiz veri, bilgisayar destekli tahmin programlarının doğru kullanılması gibi konulara önem verilmelidir.

Sağladığı birçok avantaj nedeniyle bu bilgisayar yazılımları hem jeoloji hem de maden mühendisleri tarafından yaygın olarak kullanılmaktadır. Madencilik sektöründe mühendislerin ihtiyaçlarına karşılık veren oldukça fazla yazılım bulunmaktadır. Bu yazılımların en çok bilinenleri Netpromine, Surpac, Vulcan, Datamine ve Micromine adlı programlardır. Bu programlar sondajlardan elde edilen verilerle oluşturulan veritabanı sayesinde çalışma yapılan alanı üç boyutlu ortama taşıyabilme imkanı sağlarlar.

Adana- Kozan-Horzum ve Pınargözü Pb-Zn cevherleşmesi üzerine yapılan çalışmalarda cevherleşmenin sfalerit, galenit, pirit, kalkopirit, simitsonit, zinkit, limonit, kalsit, barit ve kuvars parajenezine sahip olduğunu ve Orta Kambriyen yaşlı kireçtaşı içerisinde D-B, KB-GD gidişli faylarda, tabaka aralarında, kırık ve karstik boşluklarda muhtemelen hidrotermal olarak yerleştiğini belirtmişlerdir Yöredeki birincil sülfidli cevherlerin gömülü bir granitik sokulumdan doğrudan veya dolaylı olarak beslenen cevherli çözeltilerle ilişkili olabileceğini Birincil cevher oluşumunun olasılı yaşı Paleosen-Alt Eosen olup, karbonatlı cevher oluşumları ise birincil cevherlerin Miyosen sonrasındaki oksidasyon zonu zenginleşmelerine bağlı oluşmuşlardır [1-2].

Dama [3], Taşınmış (karbonatlı) cevherlerin yumrulu kireçtaşı seviyesi hariç Harapkayası formasyonunun diğer bütün seviyeleri içinde görüldüğünü, altında ve üzerinde yer alan birimlere göre daha geçirgen olan gri veya masif kireçtaşları, cevher getiren akışkanların yukarı doğru göçüne elverişli bir kanal ve kapan görevi gördüklerini, çoğunlukla D-B doğrultulu fayları seçerek gelen hidrotermal eriyiklerin bu faylar ve yakın çevresindeki uygun yan kayaçlar (karbonat kayaları) içerisinde Mississippi Vadisi Tip (MVT) art-oluşumlu ve düşük sicaklıklı $\left(80-200{ }^{\circ} \mathrm{C}\right)$, tabakaya paralel (stratabound) cevherleşmeler oluşturdukları belirtmişlerdir.

Akyüz [5] ise Horzum ve Pınargözü sahalarında alınan karbonatlı ve sülfürlü cevher örneklerinden jeokimyasal analizleri yaparak incelemiştir. Cevherleşmenin gömülü intrüzifle ilişkili Karbonat Ornatım Tip olabileceğine işaret etmiştir.

Bölgenin karmaşık olan jeolojik yapısı ve cevherleşlerin oluşum kökenine ait farklı çalışmalar yapılmıştır. Bu araştırma ile güncel jeolojik ve jeokimyasal verilerle Kaynak tahminine veri sağlayacak 3 boyutlu cevher modelleme çalışmaları, toplam 55752,45 m uzunlukta 470 adet sondaj verisi kullanılarak Micromine programı ile değerlendirilmiştir.

\section{MATERYAL VE METOD}

\subsection{Materyal}

Horzum-Kozan (Adana) Bölgesinde yer alan Kurşun-Çinko Cevherleşmesi modelleme çalışmaları, 470 adet karotlu sondaj verileri kullanılarak yapılmıştır. 
İnceleme alanı Adana İli’nin yaklaşık $97 \mathrm{~km}$ kuzeydoğusunda, Kozan İlçesi'nin yaklaşık 27 km kuzeyinde yer almaktadır. Ruhsat sahası 1/25000 ölçekli Adana- M35-c1 ve M35 c2 paftalarında yer almaktadır. Ruhsat sahası Horzum Maden ve Arama A.Ş. ye aittir.

Cevherleşme kristalize kireçtaşı, dolomit ve dolomititik kireçtaşlarından oluşan orta Kambiriyen yaşlı Çaltepe formasyonu içerisinde, kireçtaşını ve dolomitik kireçtaşını kesen yapısal hatların kontrolünde ve bu hatlarda gelişen karstik alanlarda oluşmuştur. Cevherleşmeler genel olarak bölgede hakim ana yapısal hat olan K-G doğrultulu ana fayları kesen D-B ve KB-GD doğrultulu hatlarda, huni şekilli geometriye sahip mercekler şeklinde gelişmiştir. Mineralizasyonların ornatımla yerleşmesi, ana-iz element içerikleri, mineral birlikleri, izotop çalışmaları ve sıvı kapanım verileri sonuçlarına göre cevherleşmenin gömülü intrüzifle ilişkili Karbonat Ornatım Tip olabileceği belirtilmektedir [4].

\subsection{Metod}

Kaynak tahmini süreci, jeolojik veriler, karot verimi, jeoteknik veriler, mineral özelikleri, numune ve analiz verileri, yoğunluk verileri gibi birçok verinin uygun bir veritabanı oluşturulmasıyla başlar. Jeolojik rezerv hesapları bu veriler kullanılarak yapılır.

Micromine programından (Akmetal AŞ) yararlanabilmek için Koordinat (sondaj konumu) tablosunun hazırlanması gerekmektedir. Koordinat tablosu her bir sondajin konumunu $(\mathrm{x}, \mathrm{y}, \mathrm{z})$ ve derinlik değerlerini içerir eder. Doğrultu ve eğim değerleri de koordinat tablosuna girilebilir. Koordinat tablosunun dişında 3 boyutlu cevher modellemesini yapabilmemiz için analiz sonuçlarının yer aldığı analiz tablosu da oluşturulmalıdır. Bu tabloda sondaj kuyu isimleri, cevherli derinlik ve tenör gibi değerler bulunur. Bütün bu ham veriler sayısal ortama alınıp görsel hale getirildikten sonra hem sondaj kesitleri hem de topoğrafya kesitleri alınarak modelleme aşamasına geçilir. Micromine yazılımı yardımıyla cevher modelleme adımlarını aşağıdaki gibi sıralayabiliriz (Şekil 1).

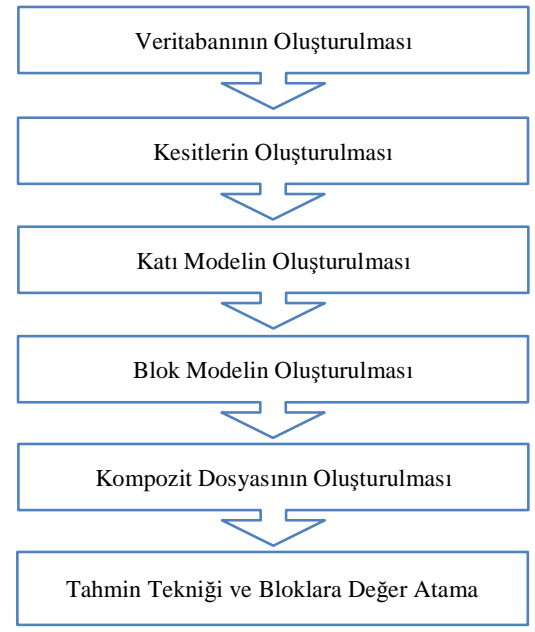

Şekil 1. Cevher modelleme adımları

Cevherin tenör değerlerine göre bloklara ayrilması ile elde edilen blok model, oluşturulan katı modelin ekonomik olarak değerlendirilmesindeki hata payını en aza indirmek için tasarlanır. Oluşturulan bloğun analiz değerlerinin belirlenmesi için programda "inverse distance" (mesafenin tersi), "ordinary kriging" (normal kriging) yöntemleri bulunmaktadır. Veri tabanının istatistiksel analizi, interpolasyon yöntemi olarak "uzaklığın tersi ile ağırlıklandırma" (inverse distance weighting) yönteminin uygun olduğunu göstermiştir. $\mathrm{Bu}$ nedenle kaynak tahmininde uzaklığın tersi (ID) ile ağırlıklandırma metodu kullanılmıştır.

\section{ARAŞTIRMA BULGULARI}

\subsection{Bölgesel Jeolojisi}

Doğu Toroslar'ın batı bölümünde, Adana ilinin kuzeydoğusunda, Kozan-Feke ilçeleri arasında kalan inceleme alanında, birbirleriyle stratigrafik ve tektonik ilişkili farklı yaş, ortam ve kayaçlar ile temsil edilen allokton konumlu farklı yapisal birimler bulunur. Birimler, Tersiyer ve Kuvaterner yaşlı çökeller tarafından açısal uyumsuz olarak örtülür. Kozan-Feke-Mansurlu arasında; İnfrakambriyen-Paleosen (?) yaşı, Görbiyes Dağı Birliği ile İnfrakambriyen-Geç Kretase yaşlı Geyikdağı Birliği bulunmaktadır [2-3] (Şekil 2). 
Birbirlerinden farklı stratigrafik ve yapısal özellikler gösteren Geyikdağı Birliği, alttan üste doğru Katrantepe dilimi ve Feke birimi ile temsil edilir. Katrantepe dilimi ise alttan üste doğru; kumtaşı, silttaşı ve kiltaşından oluşan İnfrakambriyen yaşlı Kozan formasyonu; İnfrakambriyen (?)-Erken Kambriyen yaşlı İçmetepe formasyonu; kuvarsitlerden oluşan Erken Kambriyen yaşlı Zabuk formasyonu ile dolomit ve kireçtaşlarından oluşan Orta Kambriyen yaşlı Çaltepe formasyonundan meydana gelir. Katrantepe dilimini tektonik olarak Feke birimi üzerler [3]. Katrantepe dilimini tektonik olarak üzerleyen Feke birimi çalışma sahasında; kumtaşı, silttaşı, kiltaşı ve kuvarsitten oluşan İnfrakambriyen yaşlı Kozan formasyonu; silttaşı, kumtaşı, çamurtaşı, kuvarsit, kireçtaşı ve dolomitten oluşan İnfrakambriyen (?)-Erken Kambriyen yaşlı İçmetepe formasyonu; kuvarsitten oluşan Erken Kambriyen yaşlı Zabuk formasyonu; dolomit, dolomitik kireçtaşı ve yumrulu kireçtaşından oluşan Orta Kambriyen yaşlı Çaltepe formasyonu; yumrulu görünümlü alacalı kireçtaşı, silttaşı, kumtaşı ve şeyllerden oluşan Geç Kambriyen-Erken Ordovisiyen yaşlı Seydişehir formasyonu ile temsil edilir. Çalışma alanında Zabuk formasyonu, İçmetepe formasyonu ve Kozan formasyonu gözlenmemektedir. $\mathrm{Bu}$ bölgelerde istif alttan üste doğru Kaotik Seri ile Geyikdağı birliğine ait Çaltepe formasyonu ve Seydişehir formasyonundan oluşur.



Şekil 2. İnceleme alanının stratigrafik kesiti [3] 


\subsection{Modelleme}

Modelleme için, toplam 55752,45 m uzunlukta 470 adet sondaj ve 10166 adet analizi yapılmış numune verisi kullanılmıştır. Sondaj verilerine ait bilgiler Çizelge 1'de verilmiştir. Hem yüzey hem de yer altı sondaj istasyonlarında açılı ışınsal sondajlar yapılmıştır. Hem yan hem de dikey düzlemlerde sondaj gerçekleştirilmiştir. Böylece elde edilen sondaj verilerinden yararlanılarak, sondajlarla sınırlandırılmış alan için bir kaynak tahmini yapılmıştır.

Çizelge 1. Sondajlara ait bilgiler ve modelleme tekniği

\begin{tabular}{|c|c|c|c|}
\hline $\begin{array}{c}\text { Sondaj } \\
\text { Sayıs1 }\end{array}$ & $\begin{array}{c}\text { Toplam } \\
\text { Metraj } \\
(\mathrm{m})\end{array}$ & $\begin{array}{c}\text { Numune } \\
\text { Sayısı }\end{array}$ & $\begin{array}{c}\text { Modelleme } \\
\text { Tekniği }\end{array}$ \\
\hline 470 & 55752,45 & 10166 & $\begin{array}{c}\text { Uzaklığın tersi } \\
\text { (ID) ile } \\
\text { ağırlıklandırma }\end{array}$ \\
\hline
\end{tabular}

Katı model oluşturabilmek için, öncelikle kesitler alınmıştır. Kesit almada önemli kavramlardan biri kesitin yönüdür. $\mathrm{Bu}$ çalışmada kesit yönü belirlenirken cevherin duruşu göz önünde bulundurulmuş ve Kuzeybat1-Güneydoğu yönünde alınmıștır. Saha, sondaj kuyularına denk getirilerek oluşturulan tesir mesafesi $10 \mathrm{~m}$ olan birbirine paralel 49 adet enine kesit alınarak dijital olarak eşit aralıklara bölünmüştür (Şekil 3). Cevher yatağının sınırlarını belirlemek için oluşturulan kesitler Micromine paket programın DTM (Digital Terrain Model) modülü kulanılarak 3 boyutlu cevher katı modeli oluşturulmuştur. Cevher gövdesini sınırlandırmak için jeolojik eşik değer $\% 5 \mathrm{Zn}$ alınmıştır.

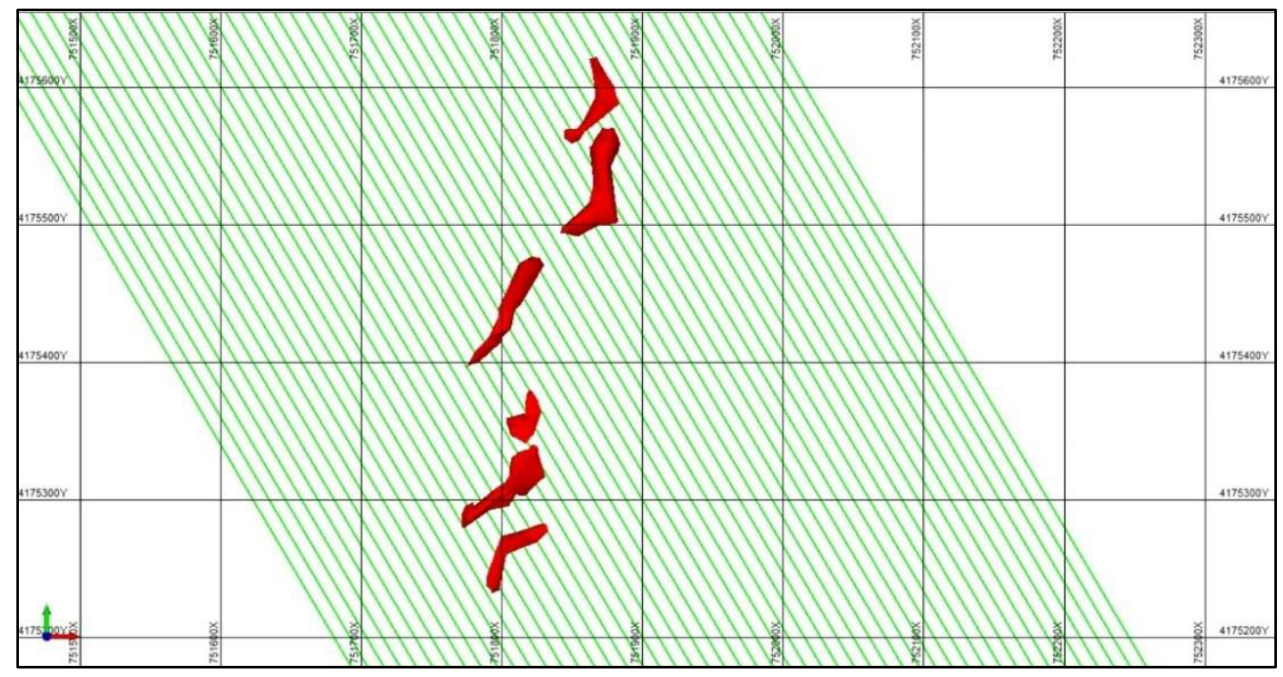

Şekil 3. Kesit çizgilerinin görünümü

Oluşturulan katı model artık hacim bilgisi vermekte ve daha sonra yapılacak tüm işlemlerde kullanılacak blok modelin oluşturulmasına olanak sağlayacaktır. $\mathrm{Bu}$ aşamada cevherin ortalama yoğunluğu da sisteme değişken olarak girilerek cevherin miktarı hesaplanabilir fakat bu tüm cevher bloğu için hesaplandığından sağlıklı bir bilgi olmayacaktır. Bu hesaplama ancak blok içindeki cevher yerini belirlemeye yönelik arama elipsoidi oluşturulduktan sonra blok model tasarlanarak yapılabilir. Cevherin tenör değerlerine göre bloklara ayrılması ile elde edilen blok model, oluşturulan katı modelin ekonomik olarak değerlendirilmesindeki hata payını en aza indirmek için tasarlanır (Şekil 4). 


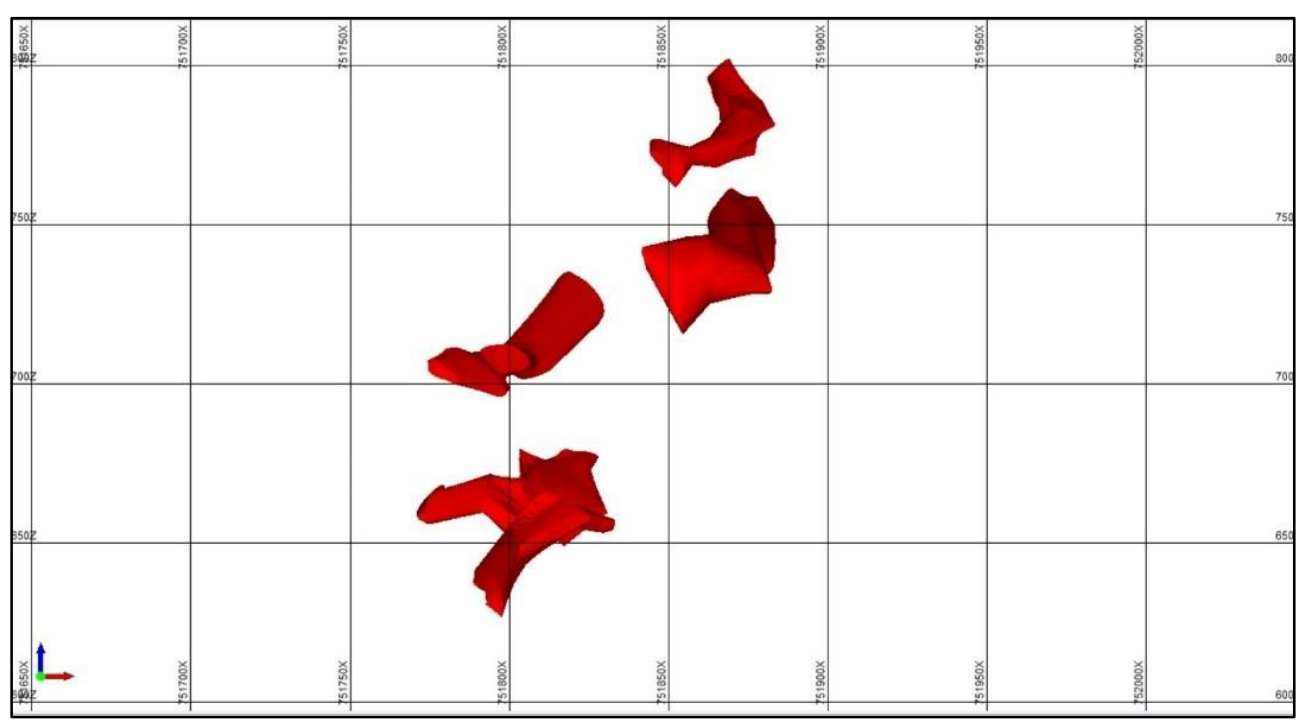

Şekil 4. Oluşturulan cevher katı modelin kuzeyden görünümü

Blok modele sondajlardan elde edilen değerler atanarak, her bloğun içeriğini hesaplamak için hesaplamalara dahil edilmesi gerekir. $\mathrm{Bu}$ nedenle önce ortalama interval aralığı bulunmuş ve bu kompozitleme işlemi yapılmıştır. Tenör aralığa göre kompozit analiz dosyası ve interval analizlerinin interval boyutuna göre ağırlıklı olarak dosyası oluşturulurmuştur (Şekil 5).

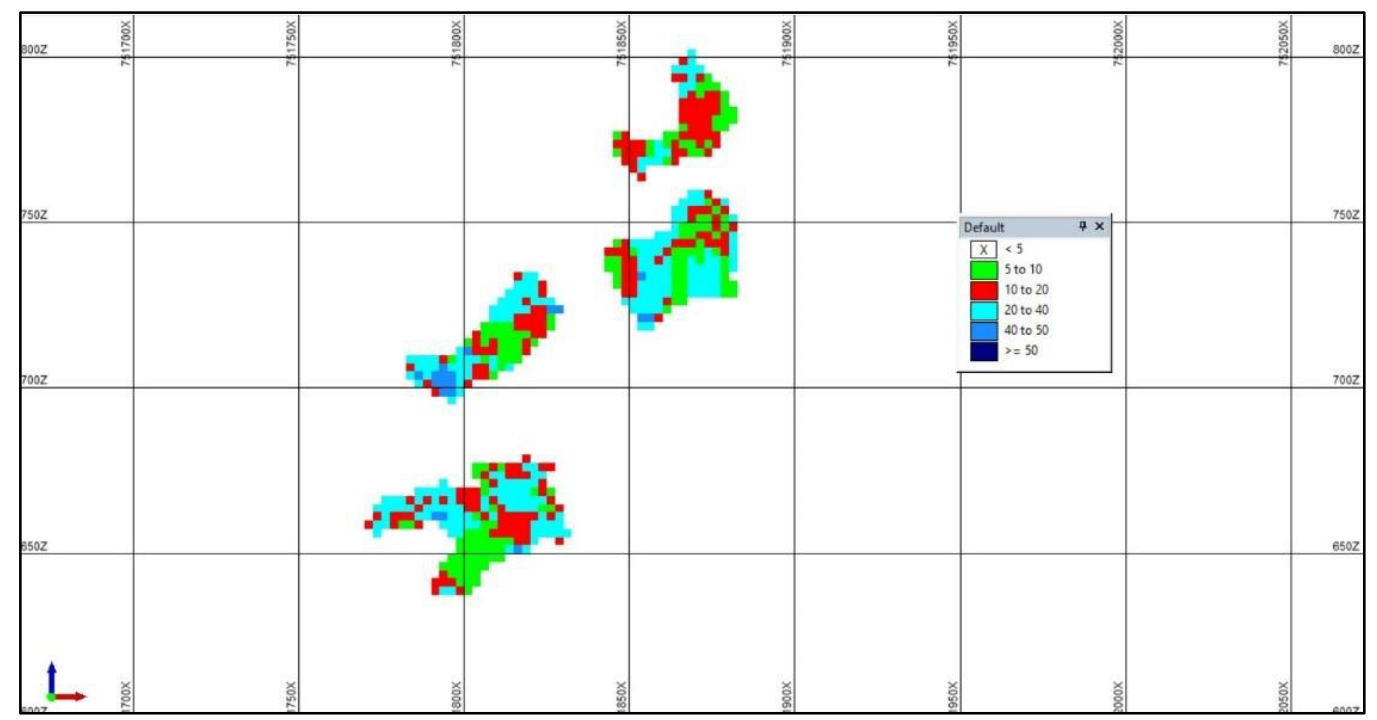

Şekil 5. Blok modelin kuzeyden görünümü

Zn içeriğine ait genel istatistikler gözden geçirilmiş ve numune uzunluklarının \%52'sinin 0,0-1,0 $\mathrm{m}$ aralıklarla alındığını tespit edilmiştir. Ortalama uzunluk $0,77 \mathrm{~m}$ ve ortanca uzunluk
0,90 m olarak belirlenmiştir. Bu sonuçlara bağl1 olarak kompozitlemede kullanilacak ortalama aralık $1 \mathrm{~m}$ olarak alınmıştır. Bütün bunlardan sonra hesaplanıp değer atanacak bloklar ve hesaplamada 
kullanılacak değerler (kompozit yapılıp ve ağırlıklarıları belirlenmiş analiz değerleri) hazır olduğunda bloklara uzaklığın tersi yöntemi ile tenör atama işlemine geçilmiştir.

Search elipsoidi kullanılarak hesaplamada kullanılacak verilerin hangi yönteme göre belirleneceği bilgisayara tanımlanmıştır. Searh elipsoidi bloğun ortasına oturur ve tanımlanmış yönteme göre elipsoid içerisine giren gerçek analiz değerlerini dikkate alarak hesaplama yapar ve hesapladığı değeri bloğa atar.

Blok model yöntemiyle yapılan hesaplamalarda Horzum Kurşun-Çinko yatağında \%5 üzeri tenörde 108000 ton cevher rezerv tespiti yapılmıştır. Bu rezervin tenör aralıklarına göre miktar ve ortalama tenör dağılımları Çizelge 2-5'te verilmiştir.

Çizelge 2. Zn Tenör aralıklarında rezerv dağılımı

\begin{tabular}{|c|c|c|c|c|c|}
\hline \multicolumn{2}{|c|}{$\%$} & $\begin{array}{c}\text { Hacim } \\
\left(\mathrm{m}^{3}\right)\end{array}$ & $\begin{array}{c}\text { Miktar } \\
(\text { ton})\end{array}$ & $\begin{array}{c}\text { Yoğunluk } \\
\left(\mathrm{t} / \mathrm{m}^{3}\right)\end{array}$ & $\begin{array}{c}\mathrm{Zn} \\
(\%)\end{array}$ \\
\hline 5 & 10 & 7250,00 & 19575,00 & 2,7 & 7,34 \\
\hline 10 & 20 & 11359,38 & 30670,31 & 2,7 & 14,76 \\
\hline 20 & 40 & 17031,25 & 45984,38 & 2,7 & 29,12 \\
\hline 40 & 50 & 2250,00 & 6075,00 & 2,7 & 43,27 \\
\hline 50 & 100 & 46,88 & 126,56 & 2,7 & 53,04 \\
\hline
\end{tabular}

Çizelge 3. Pb Tenör aralıklarında rezerv dağılımı

\begin{tabular}{|c|c|c|c|c|c|}
\hline \multicolumn{2}{|c|}{$\%$} & $\begin{array}{c}\text { Hacim } \\
\left(\mathrm{m}^{3}\right)\end{array}$ & $\begin{array}{c}\text { Miktar } \\
(\text { ton })\end{array}$ & $\begin{array}{c}\text { Yoğunluk } \\
\left(\mathrm{t} / \mathrm{m}^{3}\right)\end{array}$ & $\begin{array}{c}\mathrm{Pb} \\
(\%)\end{array}$ \\
\hline 5 & 10 & 1234,38 & 3332,81 & 2,7 & 7,0 \\
\hline 10 & 20 & 703,13 & 1898,44 & 2,7 & 15,49 \\
\hline 20 & 40 & 125,00 & 337,50 & 2,7 & 24,75 \\
\hline 40 & 50 & 0,00 & 0,00 & 2,7 & 0,00 \\
\hline 50 & 100 & 0,00 & 0,00 & 2,7 & 0,00 \\
\hline
\end{tabular}

Çizelge 4. Zn Tenör tonaj dağılımı

\begin{tabular}{|c|c|c|c|c|}
\hline Tenör & $\begin{array}{c}\text { Tonaj } \\
(\text { ton })\end{array}$ & $\begin{array}{c}\text { Hacim } \\
\left(\mathrm{m}^{3}\right)\end{array}$ & $\begin{array}{c}\text { Yoğunluk } \\
\left(\mathrm{t} / \mathrm{m}^{3}\right)\end{array}$ & $\begin{array}{c}\mathrm{Zn} \\
(\%)\end{array}$ \\
\hline 5 & 102431,25 & 37937,51 & 2,7 & 21,526 \\
\hline 10 & 82856,25 & 30687,51 & 2,7 & 24,878 \\
\hline 20 & 52185,94 & 19328,13 & 2,7 & 30,825 \\
\hline 40 & 6201,56 & 2296,88 & 2,7 & 43,469 \\
\hline 50 & 126,56 & 46,88 & 2,7 & 53,04 \\
\hline
\end{tabular}

Çizelge 5. Pb Tenör tonaj dağılımı

\begin{tabular}{|c|c|c|c|c|}
\hline Tenör & $\begin{array}{c}\text { Tonaj } \\
(\text { ton })\end{array}$ & $\begin{array}{c}\text { Hacim } \\
\left(\mathrm{m}^{3}\right)\end{array}$ & $\begin{array}{c}\text { Yoğunluk } \\
\left(\mathrm{t} / \mathrm{m}^{3}\right)\end{array}$ & $\begin{array}{c}\mathrm{Pb} \\
(\%)\end{array}$ \\
\hline 5 & 5568,75 & 2062,51 & 2,7 & 10,97008 \\
\hline 10 & 2235,94 & 828,13 & 2,7 & 16,88773 \\
\hline 20 & 337,5 & 125 & 2,7 & 24,75 \\
\hline 40 & 0 & 0 & 2,7 & 0 \\
\hline 50 & 0 & 0 & 2,7 & 0 \\
\hline
\end{tabular}

Çinko ve kurşun için tonaj ve ortalama tenör değeri dağılımını gösteren grafikler Şekil 6'de ve Şekil 7'te yer almaktadır.

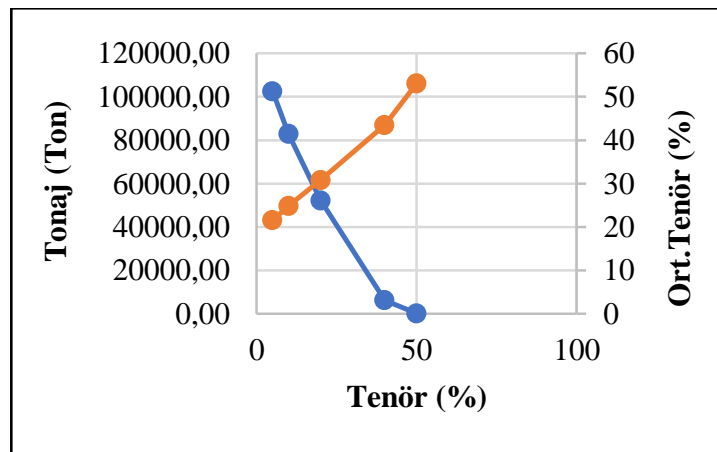

Şekil 6. Zn için tonaj-ort. tenör değeri dağılım grafiği

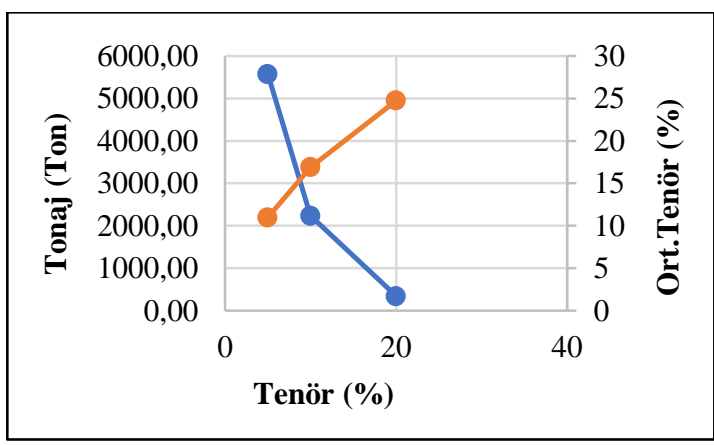

Şekil 7. $\mathrm{Pb}$ için tonaj-ort. tenör değeri dağılım grafiği

\section{TARTIŞMA VE SONUÇLAR}

Bölgede yapılan karotlu sondaj verileri kullanılarak kaynak tahminine veri sağlayacak 3 boyutlu cevher modellemesi Micromine yazılımında yapılmıştır. 
Horzum Kurşun-Çinko yatağında $\% 5$ üzeri tenörde ortalama $\% 21,53$ tenörlü 102431,25 ton çinko ve ortalama \%10,97 tenörlü 5568,75 ton kurşun olmak üzere toplam 108000 ton cevher rezervi tespit edilmiştir. Hesaplamalardan elde edilen sonuçlara göre, ortalama $\% 7,34$ tenörde 19575,00 ton, ortalama \%14,76 tenörde 30670,31 ton, ortalama \%29,12 tenörde 45984,38 ton, ortalama \%43,27 tenörde 6075,00 ton, ortalama $\% 53,04$ tenörde 126,16 ton çinko; ortalama $\% 7,00$ tenörde 3332,81 ton, ortalama \%15,49 tenörde 1898,44 ton, ortalama $\% 24,75$ tenörde 337,50 ton kurşun rezervi tespit edilmiştir. Ayrıca bu yatak için belirlenen tonajortalama tenör eğrilerinden (Şekil 4-5) faydalanılarak farklı sınır tenörlerde hangi ortalama tenör ve ne kadar cevher tonajı olduğuna dair bilgiler görülebilmektedir.

Micromine yazılımı kullanılarak yapılan bu çalışmanın neticesinde hesabı uzun süren rezerv ve bu rezervin tenör aralıklarına göre dağılımı madencilikte kullanılan bu vb. yazılımlar sayesinde çok kısa sürede hesaplanıp, tüm cevher modeline uygulanabilir olduğu görülmüştür. Ayrıca var olan hataların kısa sürede farkedilip düzeltilmesi, proje planlamada parametrelerin hızlı ve etkin olarak işlenebilmesi ve sonradan veri ekleyebilme özelliği, veri sınırlandırması olmadan çok sayıda sondaj verisinin aynı anda programa girilebilmesi, çizimlerin hassasiyetle yapılması ve bilgisayar hesaplama tekniği ile hesap hatalarının önüne geçilmesi programın sağladığı diğer avantajlardır.

Tüm bunların yanında doğru bir modelleme ve rezerv hesabı için veri tabanı oluşturma, verilerin işlenmesi ve düzenlenmesi gibi adımların büyük önem taşıdı̆̆ 1 sonucuna varılmıştır. Çünkü ortaya çıkan rakamların doğruluğunun olması gereken sıklıkta alınmış ve gereken önem verilerek değerlendirilmiş sondaj verilerine dayandığı da unutulmamalıdır.

Projeden sorumlu mühendisin teknik ve program bilgisi ile madencilikte kullanılan bu yazılımlar madencilik projelerinin daha kısa sürede, daha kesin sonuçlarla ve daha düşük maliyetlerle gerçekleşmesine olanak sağlayacaktır.
Katkı Belirleme: $\mathrm{Bu}$ çalışma, Jeoloji Mühendisliği Anabilimdalı'nda 'Horzum (Feke/Adana) Çinko-Kurşun Cevherleşmesinin 3 Boyutlu Modellemesi" konulu yüksek lisans tezi olarak hazırlanmıştır. Araştırma Çukurova Üniversitesi Bilimsel Araştırmalar Birimi tarafından FYL-2019-11742 proje kapsamında desteklenmiştir.

\section{KAYNAKLAR}

1. Bingöl, N., Yıldırım, R., 1983. Adana Kozan Horzum Çinko Madeninde Yer Altı Sondajlı Çalışma Raporu: MTA.

2. Temur, S., 1986. Horzum (Kozan-Adana) Piritli Çinko-kurşun Yataklarının Jenetik İncelemesi: Hacettepe Üniv. Yerbilimleri Derg., 12(13), 31-49.

3. Dama, 2007. Horzum (Kozan Adana) Çinko Yatağ1 Maden Jeolojisi Etüt Raporu (Yayınlanmamış)

5. Usta, D., Usta, M., Balc1, V., Kop, A., 2013. Doğu Toroslar'ın Jeolojisi ve Metalojeni (Kozan/Feke/Adana) MTA Raporu, Ankara.

6. Akyüz, F., 2019. Horzum-Kozan (Adana) PbZn Cevherleşmelerinin Kökeni, Ç.Ü. Fen Bilimleri Enst. Yüksek Lisans Tezi, Adana, 128. 